\title{
Body size and tree species composition determine variation in prey consumption in a forest-inhabiting generalist predator
}

\author{
Irene M. van Schrojenstein Lantman ${ }^{1}$ | Eero J. Vesterinen ${ }^{2,3,4}$ (D) | Lionel R. Hertzog ${ }^{1,5,6}$ \\ An Martel $^{5,6}$ | Kris Verheyen ${ }^{7}$ (D) | Luc Lens ${ }^{1}$ | Dries Bonte ${ }^{1}$ (D)
}

${ }^{1}$ Terrestrial Ecology Unit, Department of Biology, Ghent University, Gent, Belgium

${ }^{2}$ Spatial Foodweb Ecology Group, Department of Agricultural Sciences, University of Helsinki, Helsinki, Finland

${ }^{3}$ Department of Ecology, Swedish University of Agricultural Sciences, Uppsala, Sweden

${ }^{4}$ Department of Biology, University of Turku, Turku, Finland

${ }^{5}$ Thünen Institut for Biodiversity, Braunschweig, Germany

${ }^{6}$ Department Pathology, Bacteriology and Avian Diseases, Ghent University, Merelbeke, Belgium

${ }^{7}$ Forest \& Nature Lab, Department of Environment, Ghent University, Gontrode, Belgium

Correspondence

Dries Bonte, Terrestrial Ecology Unit, Department of Biology, Ghent University, K. L. Ledeganckstraat 35, 9000 Gent, Belgium. Email: dries.bonte@ugent.be

Funding information Concerted Research Actions-Special Research Fund-Ghent University; SPINCITY, Grant/Award Number: G080221N

\begin{abstract}
Trophic interactions may strongly depend on body size and environmental variation, but this prediction has been seldom tested in nature. Many spiders are generalist predators that use webs to intercept flying prey. The size and mesh of orb webs increases with spider size, allowing a more efficient predation on larger prey. We studied to this extent the orb-weaving spider Araneus diadematus inhabiting forest fragments differing in edge distance, tree diversity, and tree species. These environmental variables are known to correlate with insect composition, richness, and abundance. We anticipated these forest characteristics to be a principle driver of prey consumption. We additionally hypothesized them to impact spider size at maturity and expect shifts toward larger prey size distributions in larger individuals independently from the environmental context. We quantified spider diet by means of metabarcoding of nearly $1,000 \mathrm{~A}$. diadematus from a total of 53 forest plots. This approach allowed a massive screening of consumption dynamics in nature, though at the cost of identifying the exact prey identity, as well as their abundance and putative intraspecific variation. Our study confirmed A. diadematus as a generalist predator, with more than 300 prey ZOTUs detected in total. At the individual level, we found large spiders to consume fewer different species, but adding larger species to their diet. Tree species composition affected both prey species richness and size in the spider's diet, although tree diversity per se had no influence on the consumed prey. Edges had an indirect effect on the spider diet as spiders closer to the forest edge were larger and therefore consumed larger prey. We conclude that both intraspecific size variation and tree species composition shape the consumed prey of this generalist predator.
\end{abstract}

\section{KEYWORDS}

edge effects, Metabarcoding, predator-prey interaction, prey size spectrum $\mu$, tree diversity 


\section{1 | INTRODUCTION}

Trophic interactions are a key component of ecological networks (Landi et al., 2018; Thébault \& Loreau, 2005). Food webs are strongly impacted by the level of diet specialization of the involved consumers. With higher per capita consumption rates, specialist predators are more effective in prey control than generalists (Diehl et al., 2013), yet opportunistic and generalist predators provide stronger stabilizing effect within a food web (Gross et al., 2009). Generalist species may, however, be a collection of individuals that specialize on specific components of the full prey spectrum (Araújo et al., 2011; Bolnick et al., 2003). This intraspecific variation is known to arise from behavioral or physiological niche divergence, but equally from environmental variation constraining prey availability and the species spectrum (Bolnick et al., 2003).

Spiders are known to be important consumers of insects (Nyffeler \& Birkhofer, 2017), and many species are opportunistic and generalist predators that rely on active hunting or trapping for prey capture (Eitzinger et al., 2019). Orb-web spiders build vertical webs from silk to intercept flying prey, from small insects to smaller vertebrates (e.g., Brooks, 2012). As interception feeders, their prey spectrum is by definition strongly determined by the environment. The diet of generalist and opportunistic predators is therefore expected to reflect the species richness of the prey community (Bison et al., 2015; Eitzinger et al., 2021; Schmidt et al., 2018).

Insect, and thus prey, diversity is largely structured by the plant community composition and plant diversity (Price, 2002; Rzanny et al., 2013; Scherber et al., 2010). By providing a larger variation in resources, increases in plant diversity are known to promote coexistence of herbivore and predator species (Haddad et al., 2009; Hertzog et al., 2016; O'Brien et al., 2017). Additionally, as plant diversity is linked to an increase in productivity (Hooper et al., 2005; Loreau et al., 2001), prey abundance and mean prey size should increase as well (Allen et al., 2006). Despite the general prediction of plant diversity increasing insect diversity (Scherber et al., 2010), plant species identity may have larger effects on the community composition of arthropods than its diversity per se (Vehviläinen et al., 2008; Scherber et al., 2014; van Schrojenstein Lantman et al., 2020). Equally, and independent from these primary producer dynamics, insect and thus spider prey variation can be impacted by the spatial dimensions of their habitat, especially by habitat size and isolation (Debinski \& Holt, 2000; Krauss et al., 2010). According to the trophic rank hypothesis, higher trophic levels are generally more affected by habitat fragmentation than lower trophic levels (Cagnolo et al., 2009; Hillaert et al., 2018; Holt, 2002; Martinson \& Fagan, 2014). Edge densities increase with fragmentation (Haddad et al., 2015) and are prominent drivers of insect composition (Murcia, 1995; Schmidt et al., 2017) and abundance (Debinski \& Holt, 2000; Rand et al., 2006). In forest fragments, arthropod diversity has been shown to be strongly determined by tree species diversity, identify, and patch size (Hertzog et al., 2019, Hertzog et al., 2020; Perring et al., 2021). The patch size effects are directly translated to edge effects which allow coexistence of both forest and matrix-species (e.g., Rand et al., 2006). The warmer microclimate at forest edges also favors smaller arthropods (Atkinson \& Sibly, 1997; Kingsolver \& Huey, 2008).

In general, and despite potential variation due to weather conditions and prey availability (Bonte et al., 2008; Schneider \& Vollrath, 1998; Sensenig et al., 2010; Tew et al., 2015), larger orbweb spider species (Dahirel et al., 2017) but also larger individuals of the same species (Bonte et al., 2008; Dahirel et al., 2019) build larger webs with larger mesh sizes. This allows predation on larger prey that provide essential resources for reproduction (Venner \& Casas, 2005). Since predator body size determines the maximum prey size that can be caught (as shown for spiders by Nentwig \& Wissel, 1986), large predators can be expected to expand or shift their prey composition toward larger prey (Woodward \& Hildrew, 2002). This size dependency of web-building has been demonstrated in the cross spider Araneaus diadematus. As other in species (Dahirel et al., 2017), A. diadematus may show individual-level resource specialization in relation to the prey availability by adapting web-building behavior (Schnieder \& Vollrath, 1998). Moreover, since prey capture does not automatically imply prey consumption (Janetos, 1982), the relationship between spider size and prey (size) consumption remains untested.

Describing and understanding trophic interactions in complex habitats, such as forests, rather than in experiments or simple agricultural systems are a challenging endeavor. We lack a profound understanding on the relative importance of environmental relative to intraspecific variation for realized trophic interactions in nature. We therefore engaged in an unprecedented barcoding (O'Rorke et al., 2012; Pompanon et al., 2012) of the species' gut content to understand to what extent these components of environmental variation as well as predator size determine tropic interactions of $A$. diadematus in forest fragments dominated by different proportions of Quercus robur L. (pedunculate oak), Quercus rubra L. (red oak), and F. sylvatica L. (common beech). We specifically tested the hypothesis that prey richness in the diet increases with both tree diversity, the relative availability of pedunculate oak, and forest edge proximity, due to already documented increases in prey species availability (Hertzog et al., 2020). Independent of these tree composition and spatial effects, we tested the prediction that large spiders consume larger prey and therefore have a wider (size) range of prey species in their diet. Since more diverse forests are expected to contain larger insects, an similar shift in prey consumption is expected under the assumption of orb-web spider diet to be primarily determined by prey availability rather than prey selection.

\section{2 | MATERIALS AND METHODS}

\section{1 | Study site}

This study was conducted within the TREEWEB research platform (www.treedivbelgium.ugent.be/pl_treeweb.html) situated in the fragmented landscape of northern Belgium $\left(50.899^{\circ} \mathrm{N}, 3.946^{\circ} \mathrm{E}\right.$ $\left.-50.998^{\circ} \mathrm{N}, 3.584^{\circ} \mathrm{E}\right)$. This platform consists of 53 research plots 
of $30 \times 30 \mathrm{~m}^{2}$. All have a similar land-use history (forest since at least 1,850), management (no forest management in the last decade), and soil (dry sandy-loam). Quercus robur L. (pedunculate oak), Quercus rubra L. (red oak), and Fagus sylvatica L. (common beech) are the focal tree species in these forests. Plots of the three monocultures and all possible species mixtures ( 7 different stand compositions in total) were replicated 6 to 8 times along a fragmentation gradient. Edge distance (ranging from 7.0 to $215.5 \mathrm{~m}$ ) was used as a proxy for edge effects. Edge distance was not correlated with tree diversity, neither did it differ between tree species combinations. Tree diversity was calculated by taking the exponent of the Shannon diversity index. The Shannon diversity index was calculated using the basal stem area of the tree species per plot. For more information on the setup of the study plots, see De Groote et al. (2017).

\subsection{Study species}

We sampled common orb-weaver spiders (Araneus diadematus Clerk, 1757) for this study, as they are abundant in the study area and present in all of our study plots. We collected, if possible, 20 adult female $A$. diadematus in each plot from the 29th of August till 8th of September 2016. The spiders were taken from their webs, which were located at breast height. Collected spiders were immediately killed and stored in $99.6 \%$ alcohol. In some plots, we could not collect 20 spiders, even after multiple visits. Spider size was taken by measuring the maximum width of the cephalothorax (i.e., carapace) under a stereomicroscope using a calibrated eyepiece graticule. Cephalothorax or carapace width has been a common used proxy for body size in mature spiders (Greenstone et al., 1985; Hagstrum, 1971).

\section{3 | Molecular analysis}

To establish the diet of the spiders, we used a proven metabarcoding protocol for spiders and other invertebrate predators (Eitzinger et al., 2019; Kaunisto et al., 2017; Vesterinen et al., 2013). Shortly, we extracted DNA from the spiders' abdomen using NucleoSpin ${ }^{\circledR}$ Tissue Kit (cat. nr. 740952.250, Germany). To amplify mitochondrial COI gene, we used primers ZBJ-ArtF1C and ZBJ-ArtR2C from Zeale et al. (2011). As these primers also amplify the spiders themselves, we designed a blocking primer to decrease predator amplification in favor of prey amplification (Vestheim \& Jarman, 2008). To prepare the blocking primer, we first downloaded all unique A. diadematus sequences from BOLD and GenBank and aligned them with multiple potential prey sequences using Geneious (Kearse et al., 2012). Then, we designed three primer sequences that overlapped the reverse primer ZBJ-ArtR2c and that were specific for $A$. diadematus (zero mismatches) but that did not match any potential prey. The blocking primers were tested using primer BLAST (Koressaar \& Remm, 2007; Untergasser et al., 2012; Ye et al., 2012). The best candidate (that did not bind to anything in the database except $A$. diadematus) was chosen. This primer sequence was ordered with C3 spacer modification at the 3 ' end (Aradia-R-blk-C3: 5'-CCA AAT CCC CCA ATT AAA ATA GGT ATAC3 spacer-3'). PCR conditions and library preparation followed (Kaunisto et al., 2017) and (Vesterinen et al., 2018). Shortly, the first PCR included locus-specific linker-tagged primers, and in this stage, the target gene was amplified. In the second PCR, we introduced linker-tagged indexed (different index in forward and reverse primers) adapters that were compatible with Illumina platforms and perfectly matched the linker tags in the first initial PCR. To minimize the risk of contamination, all the extraction steps were carried out in carefully cleaned lab space, using purified pipettes with filter tips. All the extraction batches included negative controls to account for contamination issues. Washing the spiders several times in $99.6 \%$ ethanol during the collection, storage, and preparation for extraction process was deemed to be appropriate for sterilization. Negative controls containing all but template DNA were included in each PCR assay. PCR products were never introduced to the pre-PCR space. All the uniquely dual-indexed reactions were pooled and purified using SPRI beads as in Vesterinen et al. (2016). The pool in this study was combined with a similarly prepared pool (from a vertebrate dietary analysis) to increase nucleotide diversity in the sequencing and to lower costs per project. Sequencing was performed by Macrogen Korea (Macrogen Inc., Seoul, Rep. of Korea) using HiSeq4000 with TruSeq 3,000 4,000 SBS Kit v3 chemistry and 151 bp paired-end read length following HiSeq 3,000 4,000 System User Guide (Document \#15066496 v04 HCS 3.3.52).

After sequencing, the reads separated by each original sample were uploaded on CSC servers (IT Center for Science, www.cSC. fi) for trimming and further analysis. Trimming and quality control of the sequences were carried out as in Vesterinen et al. (2018). Briefly, paired-end reads were merged, trimmed, and collapsed using 64-bit software VSEARCH (Rognes et al., 2016). For chimerafiltering, denoising, and clustering into ZOTUs ('zero-radius OTU'), we used 32-bit USEARCH (Edgar, 2010; Edgar \& Flyvbjerg, 2015). Before collapsing, primers were removed using software Cutadapt (Martin, 2011). Then, ZOTUs were mapped back to the original trimmed reads using VSEARCH, and finally, ZOTUs were assigned to prey taxa as explained below.

\subsection{Data preparation}

We summed the presence or absence of each prey taxon in each sample to end up with a frequency of occurrence (FOO) for each prey taxon. Additionally, all the frequencies were scaled to percent of occurrence as explained in Deagle et al. (2019), creating a modified frequency of occurrence (MFO). We identified prey to the species level, where possible. The ZOTUs were initially identified using local BLAST against all COI sequences downloaded from BOLD and GenBank (Altschul et al., 1990; Ratnasingham \& Hebert, 2007). 
When species name was not available but match to the database was high, we used BIN codes from BOLD (Ratnasingham \& Hebert, 2013). For details of the ZOTUs, see Data S1. To visualize the trophic interaction structures resolved by the molecular data, we used package BIPARTITE (Dormann et al., ,2008, 2009) implemented in program $R$ (R Core Team, 2018). Semi-quantitative foodwebs were constructed using percent of occurrence as explained above.

For further analysis, the cutoff threshold per ZOTU for the number of reads was set $0.05 \%$ of the total number of reads per spider, with a minimum cutoff threshold of 10 reads. A first multivariate analysis was performed to explore the variation in prey composition within the spider diet. The variation in the prey ZOTU composition within the diet of individual spiders was analyzed as a function of tree species combination, edge distance, and spider size. A distance-based redundancy analysis (Euclidean distance) using the CAPSCALE function from the RDA package (Guo et al., 2018) was applied. We performed an analysis of variance on the distance-based redundancy analysis with 1,000 permutations (PERMANOVA) to quantify the variation in prey species composition explained by the different variables. Taxonomic units (prey species) were treated as binary data (absence or presence) as the data collection and chosen setup using the metabarcoding technique does not allow a more quantitative approach. We detected DNA from potential parasitoids (e.g., Tachinid flies, Ichneumonid wasps) as well. These records were rare and can be equally part of the diet. The metabarcoding does, in the same vein, not allow separating potential DNA from species consumed by predators that are here predated by spiders (e.g., Vespidae, Staphylinidae). If some bias is created by these, we do not expect this to be associated with specific environments or size classes.

\subsection{Response variables}

Per-individual spider with known size, four diet-related response variables were calculated. Prey richness was taken to be the number of ZOTUs in the diet of each spider. For every single assigned prey ZOTU, its size (body length) was taken from literature (Data S1). Prey size was taken to be the average prey size of taxonomic units preyed by each spider. These two response variables allow us to answer the four specific hypotheses. In addition, analyses were performed with response variables to unearth possible explanations for the found patterns. Taxonomic units with a body length over $1 \mathrm{~cm}$ are considered to be of highest gain (Venner \& Casas, 2005) and could help us understand patterns arising. Prey richness of large prey was the number of taxonomic units with a body length of over $1 \mathrm{~cm}$ present in the diet of each spider. Prey size of large prey was the average prey size of taxonomic units larger than $1 \mathrm{~cm}$ present in the diet of each spider. Additional to the four individual-level response variables, we additionally calculated the Sørensen index (within-plot turnover of species composition in the diet); coefficient of variation (CV) for prey richness and $\mathrm{CV}$ for prey size were calculated at plot level.

\section{6 | Statistics and model selection}

Four models were applied to the response variables to explore different aspects of the data. $M_{\text {div }}$ was the first model in which we tested for the effects of spider size, edge distance, tree diversity, and the interacting effects of edge distance and tree diversity. The three other models were a set of models to compare to each other in order to understand the effects of spider size, edge distance, and tree species composition (Kirwan et al., 2009). The null model $\left(\mathrm{M}_{\text {null }}\right)$ includes only spider size and edge distance and assumes no effect of tree species composition. The additive model $\left(M_{\text {add }}\right)$ includes, besides spider size and edge distance, the relative basal area of each of the three focal tree species, and the intercept was forced through zero. This model assumes that tree species exert only additive identity effects. The pairwise interaction model $\left(M_{\text {pair }}\right)$ includes additionally the pairwise interactions between the relative basal areas of the focal tree species. This model assumes not only additive effects, but also interacting effects between the tree species. The three composition models $\left(M_{\text {null }}, M_{\text {add }}\right.$, and $\left.M_{\text {pair }}\right)$ were compared with each other to understand in which way the tree species composition impacted on the diet-related response variables. The model with the lowest AICc (obtained using the AICcmodavg package by (Mazerolle, 2017)) was considered the best. Spider size, edge distance, and tree diversity were scaled around their mean in all models (Schielzeth, 2010). Spider size was excluded as an explanatory variable from the models applied to spider size itself. For the plot-level mean response variables, an average plot-level spider size was included as a variable, instead of individual-level spider size.

All analyses were performed in $\mathrm{R}$, version 3.5.1 ( $\mathrm{R}$ Core Team, 2018). All models, except the models with Sørensen index and coefficients of variation as a response variables, included plot ID as a random factor. This accounts for our data structure and the potential effect of plot ID. Models with overall prey size as response variable had a negative binomial distribution (log-link) with a variance increasing quadratically to the mean, applied through the GLMMTMB package (Brooks et al., 2017). Models with the overall prey richness as response variable had a negative binomial distribution with constant variance using glm. Models with the richness of prey larger than $1 \mathrm{~cm}$ as response variable had a Poisson distribution. All other models had Gaussian distributions. All models are two-tailed and have no effect of the explanatory variables as $\mathrm{H}_{0}$.

\section{3 | RESULTS}

\section{1 | General results}

A total of 340 distinct prey species from 85 families in 8 orders and two classes were detected (Figure 1). The HiSeq 4,000 sequencing yielded 265871470 paired-end reads. After assigning these reads to unique dual indexes used in this study, and after trimming 


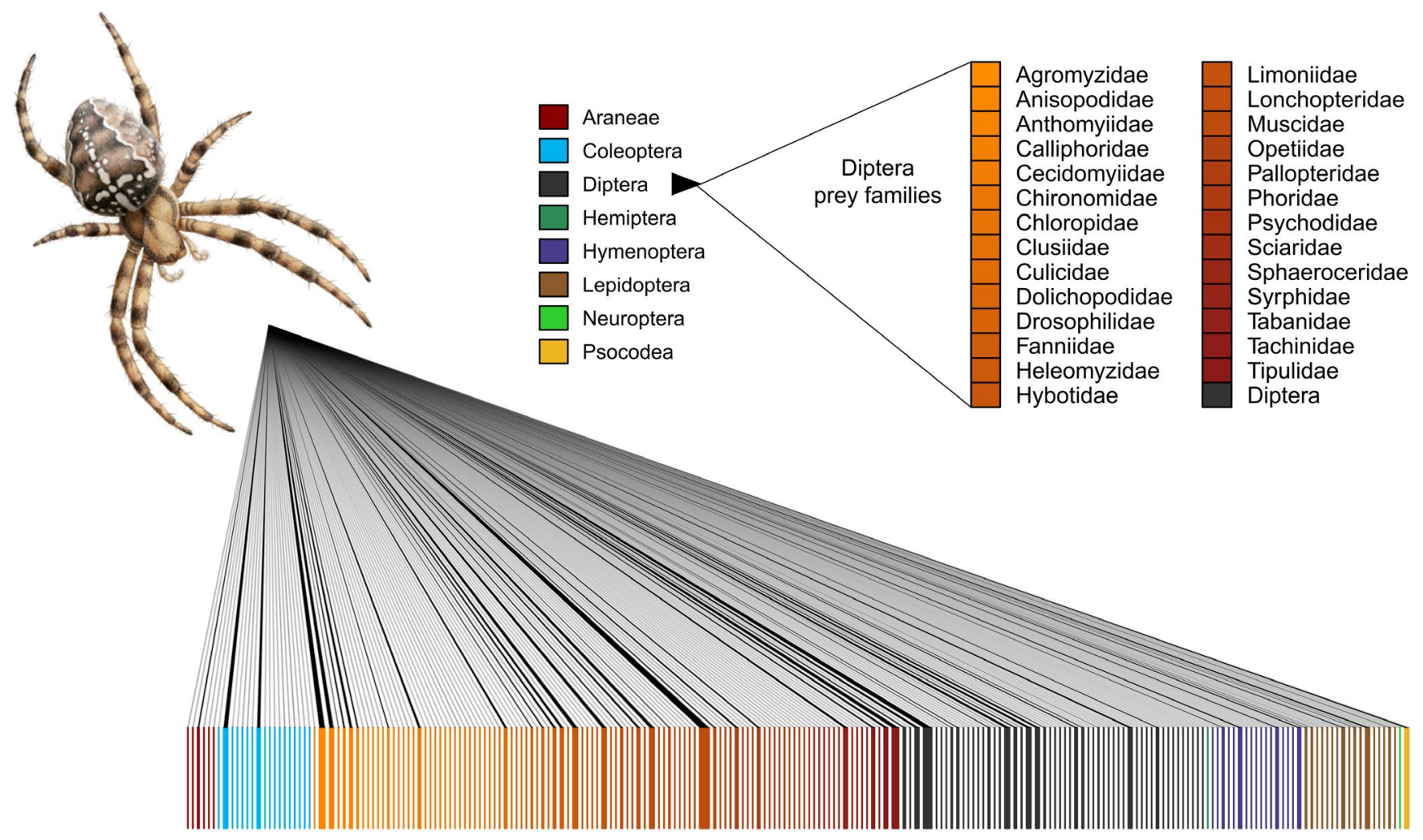

FIGURE 1 Visual representation of the taxonomic distribution and quantified strength of trophic links from Araneus diadematus to their prey. The blocks in the lower row represent prey species. A line connecting the predator with a prey represents detected predation events, and the thickness of the line represents the modified frequency of occurrences (MFO) of each predation record. See the "Data analysis" in the main text for details on the MFO

and filtering, we ended up with 5,765,096 prey reads that could be mapped to the original samples. A total of 983 spiders were included in the molecular analysis, and 857 (87.2\%) of these provided prey data after bioinformatic filtering including 298 prey species and were included in the subsequent analysis. The highest observed prey species richness within a single spider sample was 15 prey ZOTUs. The most frequent prey detected was Phaonia pallida $(N=357)$, a forest-living muscid fly. The average prey size was $7.5 \mathrm{~mm}(S D \pm 4.1)$, with only 39 prey species or genera larger than $1 \mathrm{~cm}$. For a full list of prey taxa and size data, see Data S1.

Spider cephalothorax width ranged from 2.6 to $5.31 \mathrm{~mm}$ (average of $3.57 \mathrm{~mm}$ ). Spider size decreased further from the edge; tree species identity had additive effects on spider size (Tables 13, Figure 2). Spider size was not impacted by tree diversity or the interaction between tree diversity and edge distance, but size was largest in monocultures of $Q$. robur and smallest in monocultures of F. sylvatica (Tables 1-3, Figure 2).

\section{2 | Diet composition}

The composition of prey species in spider diets is highly variable (Figure 3). Although the constrained components of the ordination only explained $2,2 \%$ of the variation in composition, spider size (PERMANOVA, $F_{\text {pseudo }}=4.41, p=0.001$ ) and tree species combination
(PERMANOVA, $F_{\text {pseudo }}=2.65, p=0.001$ ) strongly influenced prey species composition. However, all tree species compositions overlapped and showed large variation (Figure 3). Edge distance had no effect (PERMANOVA, $F_{\text {pseudo }}=1.28, p=0.127$ ). Compositional similarity of spider diet as measured by the Sørensen index was not correlated with edge distance, tree diversity, or tree species composition (Tables 1 and 3).

\section{3 | Prey richness and size}

The models including tree diversity $\left(M_{\text {div }}\right)$ revealed that edge distance, tree diversity, and the interaction between them had no impact on the four diet-related response variables: prey richness, prey size, richness of prey $>1 \mathrm{~cm}$, and size of prey $>1 \mathrm{~cm}$ (Table 1 ). In the best fitting composition models $\left(M_{\text {null }}, M_{\text {add }}, M_{\text {pair }}\right)$, edge distance had no impact on the diet-related response variables either (Table 3). Spider size had an impact on the overall prey richness and prey size, only marginally on the size of prey larger than $1 \mathrm{~cm}$, and no impact on the richness of prey larger than $1 \mathrm{~cm}$ (Table 1). A lower prey richness was detected in large spiders (Figure 4), although prey were larger in these spiders. The effect of identity of the tree species and their relative contribution to prey richness was absent, as $M_{\text {null }}$ was the best fitting model (Table 2). For prey size, there were additive effects of tree identity (Table 2). Spiders in monocultures 


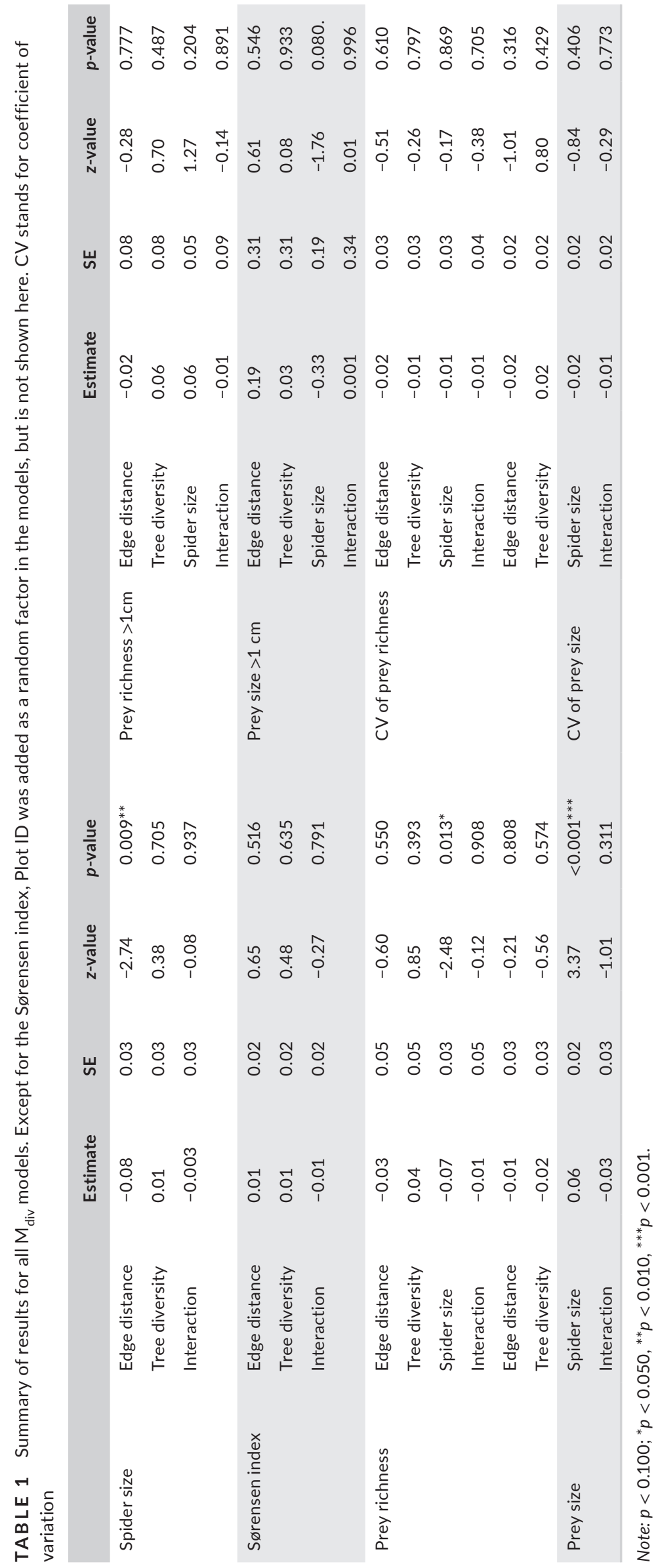


TABLE 2 Comparison of the tree species composition models for all response variables. Best fitting models based on AICc and parsimony are bold. CV stands for coefficient of variation

\begin{tabular}{|llll|} 
& \multicolumn{2}{l}{ AlCc } & \\
\cline { 2 - 4 } & $\mathrm{M}_{\text {null }}$ & $\mathrm{M}_{\text {add }}$ & $\mathrm{M}_{\text {pair }}$ \\
\hline Spider size & $1,169.26$ & $1,164.76$ & $1,164.70$ \\
\hline Sørensen index & -72.46 & -68.54 & -62.71 \\
\hline Prey richness & $4,169.50$ & $4,173.21$ & $4,175.28$ \\
\hline Prey size & $4,521.33$ & $4,512.74$ & $4,517.46$ \\
\hline CV of prey & -0.94 & 3.38 & 6.37 \\
\hline richness & & & \\
\hline CV op prey size & -58.96 & -61.93 & -56.76 \\
\hline $\begin{array}{l}\text { Prey richness } \\
>1 \mathrm{~cm}\end{array}$ & 1866.22 & 1864.35 & 1865.08 \\
\hline Prey size $>1 \mathrm{~cm}$ & $2,173.30$ & $2,173.76$ & $2,161.18$ \\
\hline
\end{tabular}

of F. sylvatica consumed the largest prey species, while spiders from Q. robur and Q. rubra monocultures had very similar sized prey (Table 3, Figure 5). Spiders inhabiting mixtures consumed prey which were the average size of the prey in the monoculture values of tree species included in the tree species composition.

Richness of prey with the highest gain (prey larger than $1 \mathrm{~cm}$ ) showed no effects of tree species identity; size of prey with the highest gain (prey larger than $1 \mathrm{~cm}$ ) did show effects of tree species identity (Tables 1-3). These large prey were proportionally most abundant in the diet of spiders from F. sylvatica monocultures (Figure 6a). Prey body size was lowest in F. sylvatica-Q. robur mixtures, relative to their anticipated size in the respective monocultures (Table 3, Figure 6b).

\subsection{Patch-level individual variation in prey consumption}

The coefficient of variation (CV) for prey richness revealed that across tree diversity, tree species composition, edge distance, and spider size, the level of specialization was the same, as none of the explanatory variables were significant (Table 1 ), and $M_{\text {null }}$ was the best fitting composition model (Table 2). The CV for prey size revealed that plots with on average larger spiders were more consistent in their consumed prey size, independent of tree diversity or edge distance (Table 1). Spiders in monocultures of $Q$. robur were least consistent in the consumed prey size, while those in F. sylvatica monoculture were most consistent (Table 3, Figure 7). Spiders inhabiting mixtures showed a level of consistency in prey size that was the average of the monoculture values of tree species included in the tree species composition (Table 1; Figure 7).

\section{DISCUSSION}

Tree diversity is an important driver of biodiversity in smaller forest fragments in Flanders (Hertzog et al., 2020), but different taxa react in different ways to the specific environmental gradients (Perring et al., 2021). We here use gut-content metabarcoding to show how changes in tree diversity, identity, and edge effects affect an important functional biodiversity component, namely trophic interactions between an orb-web spider and its prey. Tree species composition, rather than tree diversity, impacted diet. More specifically, spiders consistently consumed larger prey in monocultures of $F$. sylvatica than in other tree species compositions. Contrary to expectations, we found prey species richness in the spider diet to decrease with spider size, but the proportion of large prey items to increase. Since spiders were largest in monocultures of $Q$. robur and smallest in monocultures of F. sylvatica, but also larger closer to the forest edge, size-mediated interactions are prevalent. Plots inhabited by on average larger spiders showed lower individual variation in prey (size) consumption.

Unlike our expectation that plant diversity impacts insect diversity and trophic interactions (Price, 2002; Rzanny et al., 2013; Scherber et al., 2010), we did not find any effect of tree diversity on the richness or size of prey in the diet. This does not imply that plant diversity cannot have an impact on the diet of other predators. In one of the rare studies that focussed on trophic interactions of a generalist predator in relation to plant diversity, it was shown that the richness of consumed prey in carabid beetles did increase along an experimental grassland diversity gradient (Tiede et al., 2016). The general expectation that the diet of a predator contains more prey in prey rich habitat is based on ecological opportunism (Bison et al., 2015). Essentially, a generalist predator's diet would reflect the diversity of prey available. However, this is contradicted by the idea that the availability of more prey species allows intraspecific specialization on species (Staudacher et al., 2018). We found no support for increased specialization in more diverse forest, as the coefficient of variation in prey richness did not depend on tree diversity. It should, however, be made clear that the occurrence of ecological opportunism can neither be confirmed nor dismissed as both processes act at the individual level, and may be leveled out at the population level. In line with earlier research finding mixtures between $Q$. robur and $F$. sylvatica to harbor the highest (arthropod) diversity (Hertzog et al., 2020), we found this two-species mixture to held a different composition of species in the spiders' diet, but not richness, compared with the other tree species composition. However, if spider diet did indeed reflect the prey availability, we would expect spider diet in forests with Q. robur to have the more species and being composed of larger prey, since Q. robur is known to harbor a more diverse arthropod community (Southwood et al., 2004). This could not be demonstrated, but we need to emphasize that it remains difficult to confidently conclude whether our findings are pure reflections of the prey availability without its effective quantification, or whether some prey selection is prevalent. Indeed, larger spiders tended to be more selective in their foraging by the consumption of fewer, but larger prey species. Consumption of larger prey is likely needed to achieve their higher energy requirement (Brown et al., 2004). We can, however, not attribute the general 


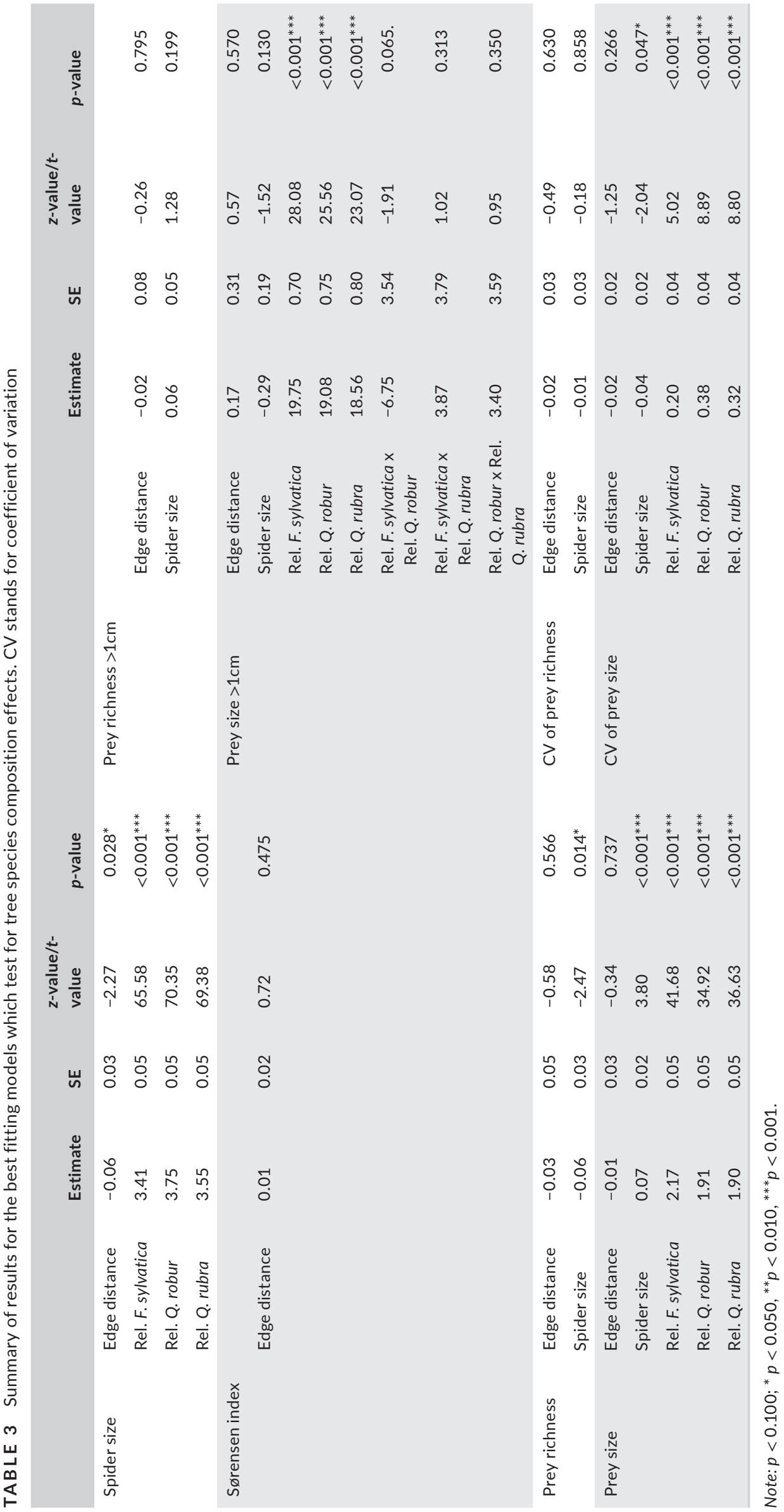



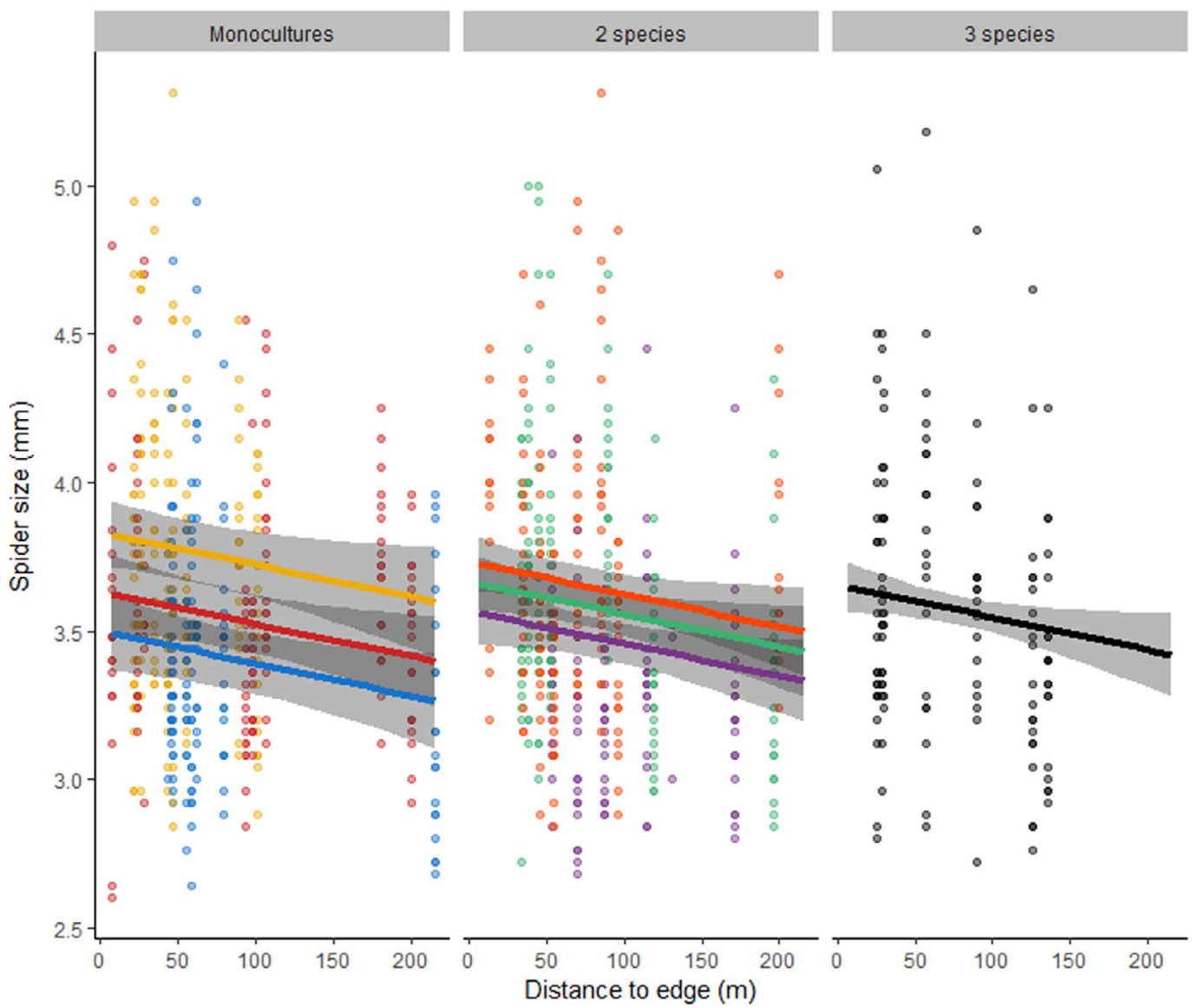

FIGURE 2 Relationship between the spider's cephalothorax size $(\mathrm{mm})$ and distance to the forest edge $(\mathrm{m})$ per tree species composition. Data points are the individual spiders $(\mathrm{N}=983)$. Lines with $95 \% \mathrm{Cl}$ are the estimated slope based on model $\mathrm{M}_{\text {add }}$. Colors refer to the tree species composition. There is a negative relationship between spider size and edge distance, and additive tree species composition effects, where mixtures are averages of each individual monoculture contributing to the mixture

FIGURE 3 Distance-based redundancy analysis on the prey composition of individual spiders. Colors refer to the different tree species compositions in which the spiders were sampled. Ellipses correspond with the standard deviation of each tree species composition centroid. Size refers to the spider size and edge to edge distance. The constrained components of the ordination (spider size, edge distance, and tree species composition) explained $2.2 \%$ of all variation in diet composition

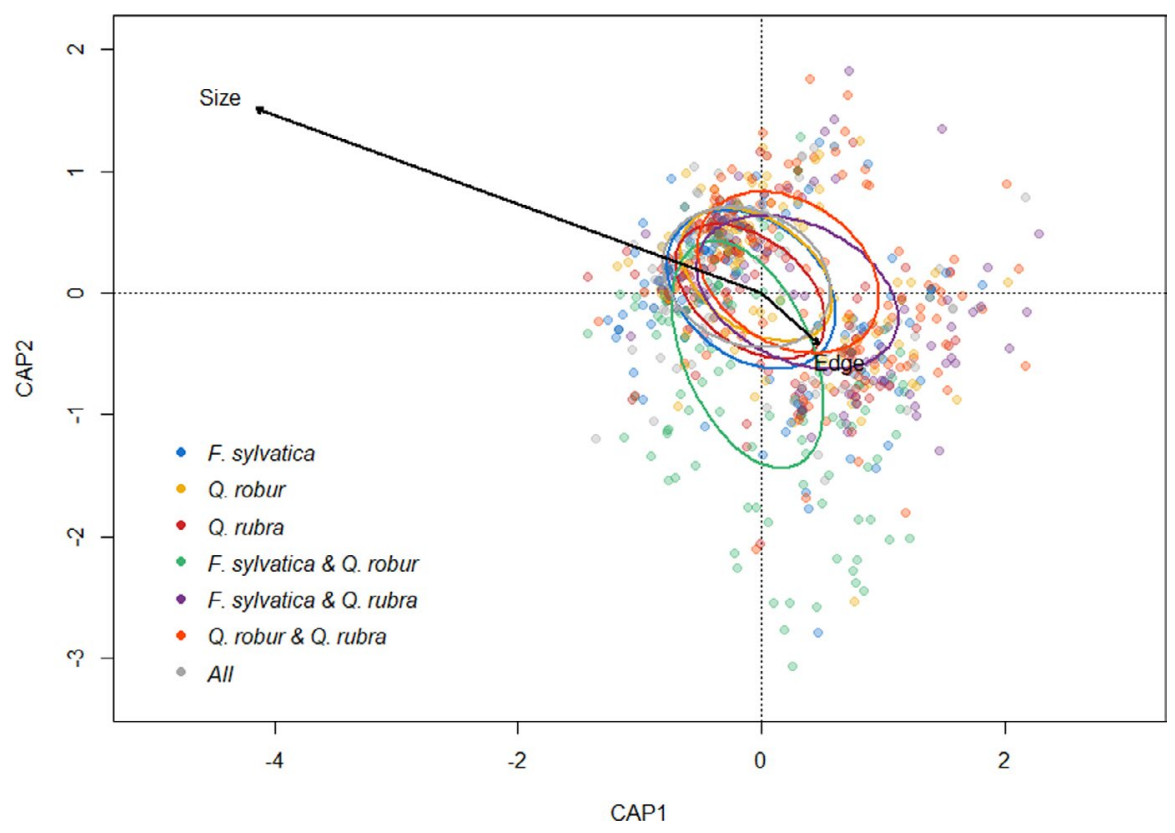

prey size increases to the selection of the largest most energyefficient prey, as prey larger than one $\mathrm{cm}$ did not show a clear relationship with spider size. Moreover, our approach does neither allow more quantitative analyses on the relative abundances, consumed biomasses, or intraspecific variation in prey size. Prey sizes could only be derived from literature, and while caught prey 


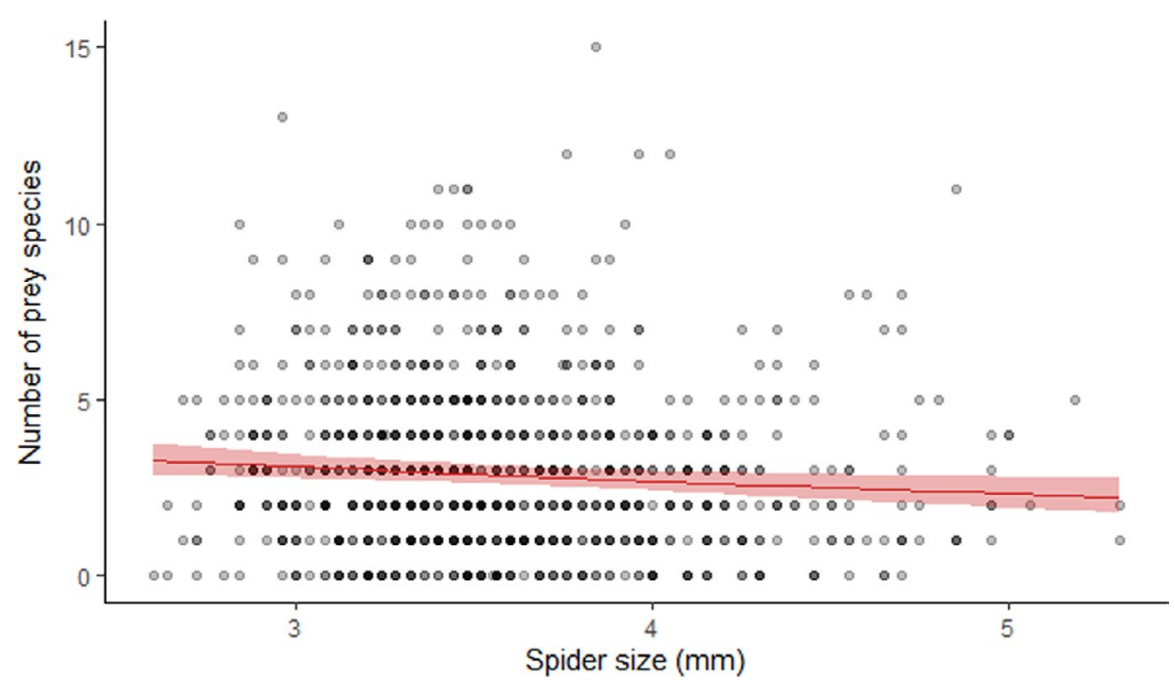

FIGURE 4 Relationship between the number of prey species in the diet of a spider and its cephalothorax size in $\mathrm{mm}$. Data points are the number of prey species per-individual spider $(n=983)$. Red line with $95 \% \mathrm{Cl}$ is the estimated slope based on model $M_{\text {div }}$
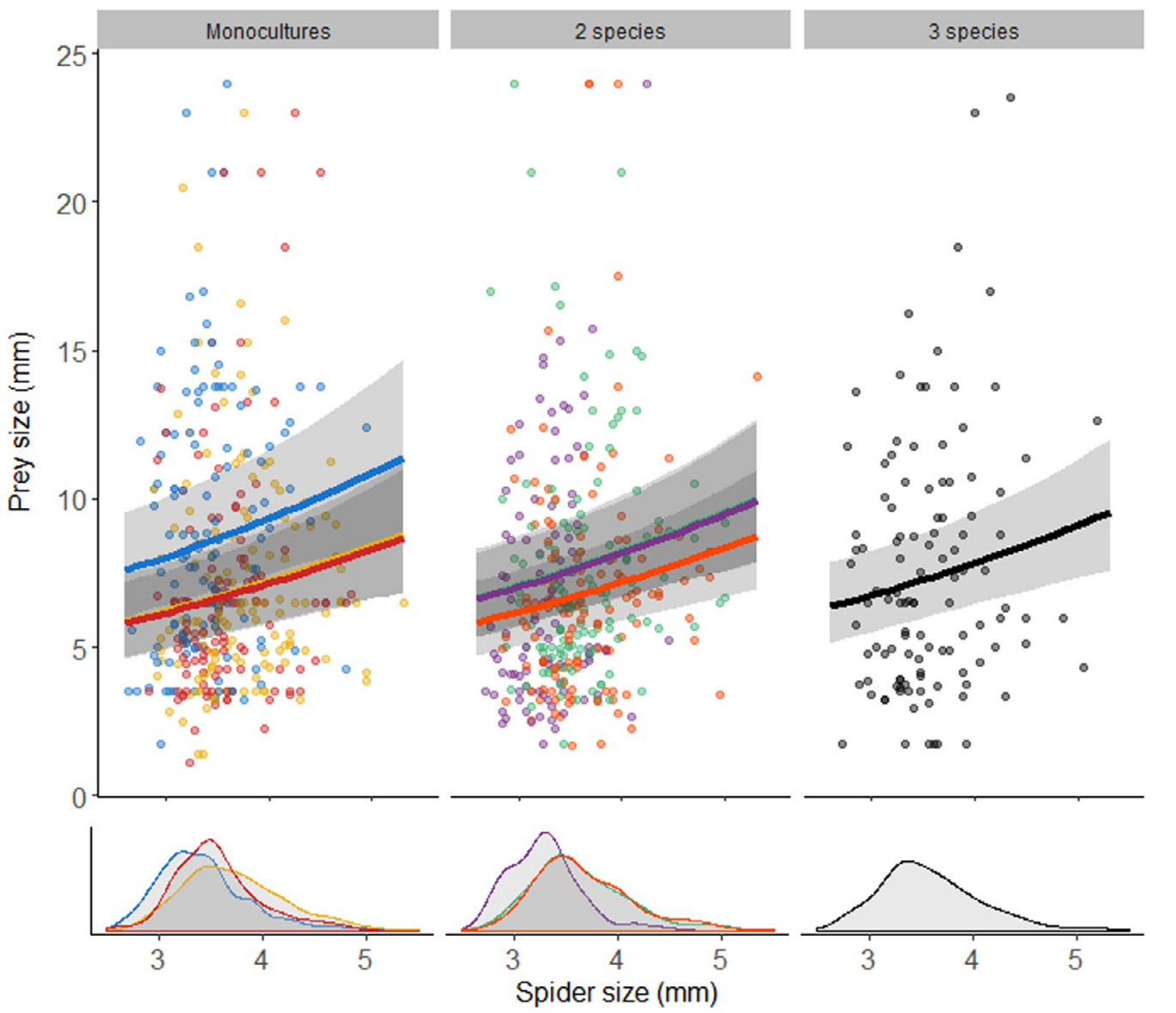

Tree species composition

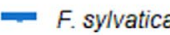

- Q. robur

- Q. rubra

- F. sylvatica \& Q. robur

- F. sylvatica \& Q. rubra

- Q. robur \& Q. rubra

- All

FIGURE 5 Relationship between the average prey size $(\mathrm{mm})$ of the species caught and the spider's cephalothorax size ( $\mathrm{mm}$ ) per tree species composition. Data points are the individual spiders $(N=983)$. Lines with $95 \% \mathrm{Cl}$ are the estimated slopes based on model $\mathrm{M}_{\text {add }}$. For estimation, edge distance was taken to be the overall average. Colors refer to the tree species composition. There is a positive relationship between average prey size and spider, and additive tree species composition effects, in which spiders from F. sylvatica monocultures catch relatively larger prey species than in the other monocultures. In mixtures, the prey size is averages of each individual monoculture contributing to the mixture. The lower part of the graph shows density plots of the spider size distribution within each tree species composition

are adult active flying stages, intraspecific variation may be substantial. Irrespective of spider size, spiders also consumed consistently large prey, and more and larger prey of high gain $(>1 \mathrm{~cm})$ in monocultures of F. sylvatica than in other tree species composition. Interestingly, monocultures of F. sylvatica also hold the smallest spiders. 
FIGURE 6 Tree species composition effect on (a) the number of prey species larger than $1 \mathrm{~cm}$ and (B) the average prey size of prey larger than $1 \mathrm{~cm}$. Open data points are the averages per plot. Red point ranges are the estimated values based on the best parsimonious model. Edge distance and spider size were taken to be the overall average. For (a), there are additive effects of the monocultures in mixtures, averaging out the number of prey species. For (b), there are pairwise interaction effects in combining F. sylvatica with $Q$. robur results in (marginally) lower prey size than expected based on the monocultures

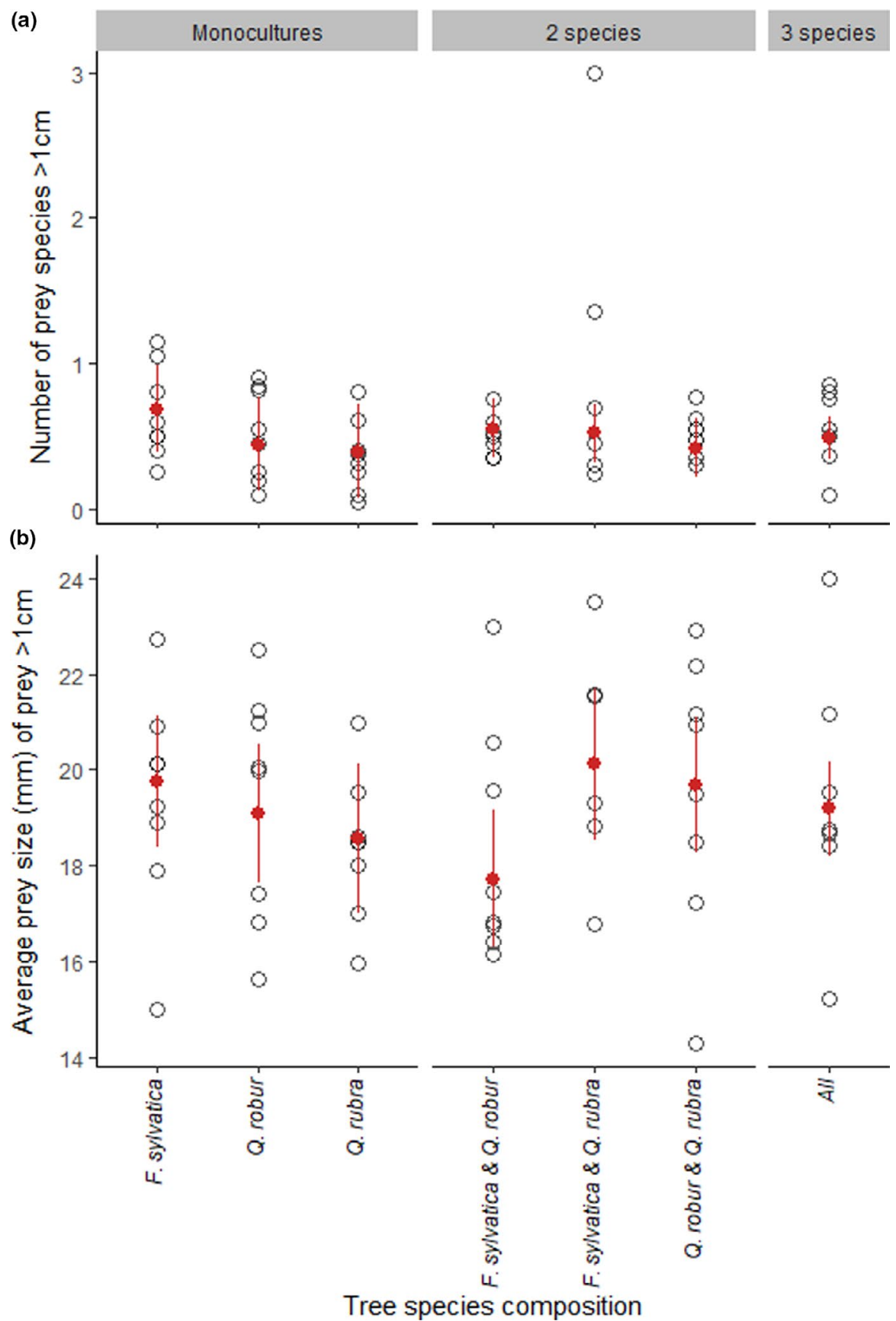

We found no changes in prey richness or composition in relation to edge proximity. A possible pattern could, however, be masked by the occurrence of larger spiders in proximity of the forest edge. Neither larger spiders close to the edge, nor the absence of larger prey species consumed close to the edge fit the expectation that the warmer forest edges could favor smaller arthropods (Atkinson \& Sibly, 1997; Kingsolver \& Huey, 2008). Wind is stronger in the forest edges (Schmidt et al., 2017). Wind damages webs, which reduces the foraging efficiency and enforces costly web repairs (Tew et al., 2015). This may select for larger spiders with higher silk production (Vollrath, 1999). It is possible that within this study a stronger effect is overlooked, as edge effects for both biotic and abiotic gradients are generally observed in first few meters from the edge (Murcia, 1995; Schmidt et al., 2017; De Smedt et al., 2018).

In conclusion, we show that an interception predator like the orb-web spider A. diadematus is not only generalist in prey capture but also prey consumption. At the individual level, however, the prey spectrum of this generalist predator is linked to body size, with larger spiders foraging on a smaller number of consistently larger prey species. Contrary to expectations from earlier research on insect diversity in forest fragments differing in tree species composition, prey species richness and size are only marginally explained by tree species composition. Edge effects on trophic relations were only indirectly prevalent through differences in spider size. 


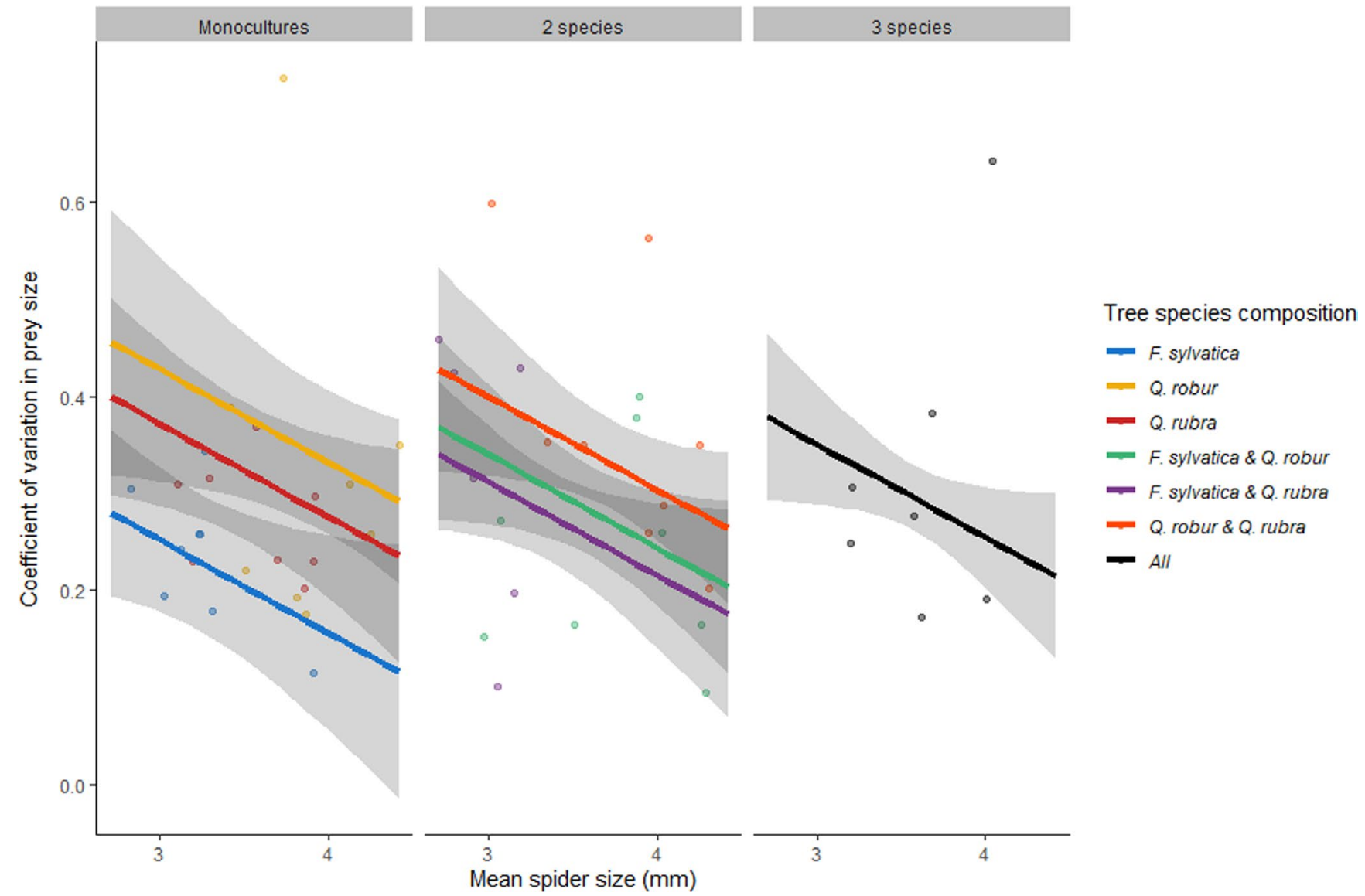

FIGURE 7 Relationship between the coefficient of variation (CV) for prey size per plot and the mean spider's cephalothorax size (mm) per plot. Data points are the individual plots $(N=53)$. Lines with $95 \% \mathrm{Cl}$ are the estimated slopes based on model $\mathrm{M}_{\text {add }}$. For estimation, edge distance was taken to be the overall average. Colors refer to the tree species composition. In plots with larger spiders, there is a stronger stability in prey size (lower CV). Additive tree species composition effects are present. The strongest stability in prey size is found in monocultures of F. sylvatica and the lowest stability in monoculture of Q. robur. In mixtures, the CV is an average of the CV of each individual monoculture contributing to the mixture

\section{ACKNOWLEDGMENTS}

We thank the research group of Tomas Roslin for providing the workspace for performing the molecular analysis, all the forest owners for their permission to conduct our sampling in their forest, Daan Dekeukeleire for many discussions, and Pieter Vantieghem for his fieldwork assistance. This study was financially supported by Concerted Research Actions-Special Research Fund-Ghent University for the UGent GOA project Scaling up Functional Biodiversity Research: from Individuals to Landscapes and Back (TREEWEB) and FWO project G080221N.

\section{CONFLICT OF INTERESTS}

The authors declare no competing interests.

\section{AUTHOR CONTRIBUTION}

Irene Lantman: Conceptualization (equal); Data curation (equal); Formal analysis (lead); Methodology (equal); Visualization (equal); Writing-original draft (equal). Eero J. Juhani Vesterinen: Data curation (equal); Formal analysis (equal); Methodology (equal); Resources (equal); Writing-original draft (equal). Lionel Hertzog: Formal analysis (equal); Project administration (equal); Writing-original draft (equal). An Martel: Conceptualization (equal); Project administration (equal); Supervision (equal); Writing-original draft (equal). Kris Verheyen: Conceptualization (equal); Data curation (equal); Funding acquisition (equal); Writing-original draft (equal). Luc Lens: Conceptualization (equal); Data curation (equal); Funding acquisition (equal); Project administration (equal); Supervision (equal); Writing-original draft (equal). Dries Bonte: Conceptualization (equal); Data curation (equal); Formal analysis (equal); Funding acquisition (equal); Investigation (equal); Methodology (equal); Project administration (equal); Resources (equal); Supervision (equal); Writing-original draft (equal).

\section{DATA AVAILABILITY STATEMENT}

All data on spider size, plot composition, and DNA sequence assemblies are available on DRYAD: https://doi.org/10.5061/dryad.7sqv9s4s3

\section{ORCID}

Eero J. Vesterinen (ID https://orcid.org/0000-0003-3665-5802 Kris Verheyen (iD https://orcid.org/0000-0002-2067-9108

Dries Bonte iD https://orcid.org/0000-0002-3320-7505 


\section{REFERENCES}

Allen, C. R., Garmestani, A. S., Havlicek, T. D., Marquet, P. A., Peterson, G. D., Restrepo, C., Stow, C. A., \& Weeks, B. E. (2006). Patterns in body mass distributions: Sifting among alternative hypotheses. Ecology Letters, 9, 630-643. https://doi. org/10.1111/j.1461-0248.2006.00902.x

Altschul, S. F., Gish, W., Miller, W., Myers, E. W., \& Lipman, D. J. (1990). Basic local alignment search tool. Journal of Molecular Biology, 215, 403-410. https://doi.org/10.1016/S0022-2836(05)80360-2

Araújo, M. S., Bolnick, D. I., \& Layman, C. A. (2011). The ecological causes of individual specialisation. Ecology Letters, 14, 948-958. https://doi. org/10.1111/j.1461-0248.2011.01662.x

Atkinson, D., \& Sibly, R. M. (1997). Why are organisms usually bigger in colder environments? Making sense of a life history puzzle. Trends in Ecology \& Evolution, 12, 235-239. https://doi.org/10.1016/S0169 -5347(97)01058-6

Bison, M., Ibanez, S., Redjadj, C., Boyer, F., Coissac, E., Miquel, C., Rioux, D., Said, S., Maillard, D., Taberlet, P., Yoccoz, N. G., \& Loison, A. (2015). Upscaling the niche variation hypothesis from the intra - to the inter - specific level. Oecologia, 179, 835-842. https://doi.org/ 10.1007/s00442-015-3390-7

Bolnick, D. I., Amarasekare, P., Araújo, M. S., Bürger, R., Levine, J. M., Novak, M., Rudolf, V. H. W., Schreiber, S. J., Urban, M. C., \& Vasseur, D. A. (2003). Why intraspecific trait variation matters in community ecology. Trends in Ecology \& Evolution, 26, 183-192. https://doi. org/10.1016/j.tree.2011.01.009

Bolnick, D. I., Svanbäck, R., Fordyce, J. A., Yang, L. H., Davis, J. M., Hulsey, C. D., \& Forister, M. L. (2003). The Ecology of Individuals: Incidence and Implications of Individual Specialization. The American Naturalist, 161, 1-28. https://doi.org/10.1086/343878

Bonte, D., Lanckacker, K., Wiersma, E., \& Lens, L. (2008). Web building flexibility of an orb-web spider in a heterogeneous agricultural landscape. Ecography, 31(5), 646-653. https://doi. org/10.1111/j.0906-7590.2008.05508.x

Brooks, D. M. (2012). Birds caught in spider webs: A synthesis of patterns. The Wilson Journal of Ornithology, 124, 345-353. https://doi. org/10.1676/11-148.1

Brooks, M. E., Kristensen, K., Benthem, K. J., Magnusson, A., Berg, C. W., Nielsen, A., Skaug, H. J., Mächler, M., \& Bolker, B. M. (2017). glmmTMB balances speed and flexibility among packages for zeroinflated generalized linear mixed modeling. The $R$ Journal, 9, 378400. https://doi.org/10.32614/RJ-2017-066

Brown, J. H., Gillooly, J. F., Allen, A. P., Savage, V. M., \& West, G. B. (2004). Toward a metabolic theory of ecology. Ecology, 85, 17711789. https://doi.org/10.1890/03-9000

Cagnolo, L., Valladares, G., Salvo, A., Cabido, M., \& Zak, M. (2009). Habitat fragmentation and species loss across three interacting trophic levels: Effects of life-history and foodweb traits. Conservation Biology, 23, 1167-1175. https://doi. org/10.1111/j.1523-1739.2009.01214.x

Dahirel, M., De Cock, M., Vantieghem, P., \& Bonte, D. (2019). Urbanizationdriven changes in web-building and body size in an orb-web spider. Journal of Animal Ecology, 88, 79-91.

Dahirel, M., Dierick, J., Cock, M. D., \& Bonte, D. (2017). Intraspecific variation shapes community-level behavioral responses to urbanization in spiders. Ecology, 98, 2379-2390. https://doi.org/10.1002/ ecy.1915

De Groote, ,. S. R. E., van Schrojenstein Lantman, I. M., Sercu, B. K., Dekeukeleire, D., Boonyarittichaikij, R., Keely Smith, H., De Beelde, R., Ceunen, K., Vantieghem, P., Matheve, H., De Neve, L., Vanhellemont, M., Baeten, L., de la Peña, E., Bonte, D., Martel, A. N., Verheyen, K., \& Lens, L. (2017). Tree species identity outweighs the effects of tree species diversity and forest fragmentation on understorey diversity and composition. Plant Ecology and Evolution, 150, 229-239. https://doi.org/10.5091/plecevo.2017.1331
Deagle, B. E., Thomas, A. C., Mclnnes, J. C., Clarke, L. J., Vesterinen, E. J., Chare, E. L. et al (2019). Counting with DNA in metabarcoding studies: How should we convert sequence reads to dietary data? Molecular Ecology, 28, 391-406.

Debinski, D. M., \& Holt, R. D. (2000). A survey and overview of habitat fragmentation experiments. Conservation Biology, 14, 342-355.

Diehl, E., Sereda, E., Wolters, V., \& Birkhofer, K. (2013). Effects of predator specialization, host plant and climate on biological control of aphids by natural enemies: A meta-analysis. Journal of Applied Ecology, 50, 262-270. https://doi.org/10.1111/1365-2664.12032

Dormann, C. F., Fruend, J., Bluethgen, N., \& Gruber, B. (2009). Indices, graphs and null models: Analyzing bipartite ecological networks. The Open Ecology Journal, 2, 7-24. https://doi.org/10.2174/1874213000 902010007

Dormann, C. F., Gruber, B., \& Fruend, J. (2008). Introducing the bipartite Package: Analysing Ecological Networks. R news, 8, 8-11.

Edgar, R. C. (2010). Search and clustering orders of magnitude faster than BLAST. Bioinformatics, 26, 2460-2461. https://doi.org/10.1093/ bioinformatics/btq461

Edgar, R. C., \& Flyvbjerg, H. (2015). Sequence analysis Error filtering, pair assembly and error correction for next-generation sequencing reads. Bioinformatics, 31, 3476-3482. https://doi.org/10.1093/bioinforma tics/btv401

Eitzinger, B., Abrego, N., Gravel, D., Huotari, T., Vesterinen, E. J., \& Roslin, T. (2019). Assessing changes in arthropod predator - prey interactions through DNA - based gut content analysis - variable environment, stable diet. Molecular Ecology, 28, 266-280.

Eitzinger, B., Roslin, T., Vesterinen, E. J., Robinson, S. I., \& O'Gorman, E. J. (2021). Temperature affects both the Grinnellian and Eltonian dimensions of ecological niches - A tale of two Arctic wolf spiders. Basic and Applied Ecology, 50, 132-143. https://doi.org/10.1016/j. baae.2021.01.001

Greenstone, M. H., Morgan, C. E., \& Hultsch, A. L. (1985). Ballooning methodology: Equations for estimating masses of sticky-trapped spiders. Journal of Arachnology, 13, 225-230.

Gross, T., Rudolf, L., Levin, S. A., \& Dieckmann, U. (2009). Generalized models reveal stabilizing factors in food webs. Science, 235, 747-750. https://doi.org/10.1126/science.1173536

Guo, Y., Hastie, T., \& Tibshirani, R. (2018) rda: Shrunken Centroids Regularized Discriminant Analysis.

Haddad, N. M., Brudvig, L. A., Clobert, J., Davies, K. F., Gonzalez, A., Holt, R. D., Lovejoy, T. E., Sexton, J. O., Austin, M. P., Collins, C. D., Cook, W. M., Damschen, E. I., Ewers, R. M., Foster, B. L., Jenkins, C. N., King, A. J., Laurance, W. F., Levey, D. J., Margules, C. R., ... Townshend, J. R. (2015). Habitat fragmentation and its lasting impact on Earth's ecosystems. Applied Ecology, 1, e1500052. https://doi.org/10.1126/ sciadv. 1500052

Haddad, N. M., Crutsinger, G. M., Gross, K., Haarstad, J., Knops, J. M. H., \& Tilman, D. (2009). Plant species loss decreases arthropod diversity and shifts trophic structure. Ecology Letters, 12, 1029-1039. https:// doi.org/10.1111/j.1461-0248.2009.01356.x

Hagstrum, D. W. (1971). Carapace width as a tool for evaluating the rate of development of spiders in the laboratory and the field. Annals of the Entomological Society of America, 64, 757-760.

Hertzog, L. R., Boonyarittichaikij, R., Dekeukeleire, D., de Groote, S. R. E., van Schrojenstein Lantman, I. M., Sercu, B. K., Smith, H. K., de la Peña, E., Vandegehuchte, M. L., Bonte, D., Martel, A., Verheyen, K., Lens, L., \& Baeten, L. (2019). Forest fragmentation modulates effects of tree species richness and composition on ecosystem multifunctionality. Ecology, 100(4), e02653. https://doi.org/10.1002/ ecy. 2653

Hertzog, L. R., Meyer, S. T., Weisser, W. W., \& Ebeling, A. (2016). Experimental manipulation of grassland plant diversity induces complex shifts in aboveground arthropod diversity. PLoS One, 11, e0148768. https://doi.org/10.1371/journal.pone.0148768 
Hertzog, L., Vandegehuchte, M., Dekeukeleire, D., Dekoninck, W. DeSmedt, P., van Schrojenstein Lantman, I., Proesmans, W., Baeten, L., Bonte, D., Martel, A. \& Verheyen, K. (2020). Mixing tree species is especially beneficial for biodiversity and forest functioning in highly fragmented landscapes. Authorea. https://doi.org/10.22541/ au.160519553.31576463/v1. [preprint]

Hillaert, J., Hovestadt, T., Vandegehuchte, M. L., \& Bonte, D. (2018). Sizedependent movement explains why bigger is better in fragmented landscapes. Ecology and Evolution, 8, 10754-10767. https://doi. org/10.1002/ece3.4524

Holt, R. D. (2002). Food webs in space: On the interplay of dynamic instability and spatial processes. Ecological Research, 17, 261-273. https:// doi.org/10.1046/j.1440-1703.2002.00485.x

Hooper, D. U., Chapin, F. S., Ewel, J. J., Hector, A., Inchausti, P., Lavorel, S., Lawton, J. H., Lodge, D. M., Loreau, M., Naeem, S., Schmid, B., Setälä, H., Symstad, A. J., Vandermeer, J., \& Wardle, D. A. (2005). Effects of biodiversity on ecosystem functioning: A consensus of current knowledge. Ecological Monographs, 75, 3-35. https://doi. org/10.1890/04-0922

Janetos, A. C. (1982). Foraging tactics of two guilds of web-spinning spiders. Behavioral Ecology and Sociobiology, 10, 19-27. https://doi. org/10.1007/BF00296392

Kaunisto, K. M., Roslin, T., Sääksjärvi, I. E., \& Vesterinen, E. J. (2017). Pellets of proof: First glimpse of the dietary composition of adult odonates as revealed by metabarcoding of feces. Ecology and Evolution, 7, 8588-8598. https://doi.org/10.1002/ece3.3404

Kearse, M., Moir, R., Wilson, A., Stones-Havas, S., Cheung, M., Sturrock, S., Buxton, S., Cooper, A., Markowitz, S., Duran, C., Thierer, T., Ashton, B., Meintjes, P., \& Drummond, A. (2012). Geneious Basic: An integrated and extendable desktop software platform for the organization and analysis of sequence data. Bioinformatics, 28, 1647-1649. https://doi.org/10.1093/bioinformatics/bts199

Kingsolver, J. G., \& Huey, R. B. (2008). Size, temperature, and fitness: Three rules. Evolutionary Ecology Research, 10, 251-268.

Kirwan, L., Connolly, J., Finn, J. A., Brophy, C., Lüscher, A., Nyfeler, D., \& Sebastià, M.-T. (2009). Diversity-interaction modeling: Estimating contributions of species identities and interactions to ecosystem function. Ecology, 90, 2032-2038. https://doi.org/10.1890/08-1684.1

Koressaar, T., \& Remm, M. (2007). Enhancements and modifications of primer design program Primer3. Bioinformatics, 23, 1289-1291. https://doi.org/10.1093/bioinformatics/btm091

Krauss, J., Bommarco, R., Guardiola, M., Heikkinen, R. K., Helm, A., Kuussaari, M., Lindborg, R., Öckinger, E., Pärtel, M., Pino, J., Pöyry, J., Raatikainen, K. M., Sang, A., Stefanescu, C., Teder, T., Zobel, M., \& Steffan-Dewenter, I. (2010). Habitat fragmentation causes immediate and time- delayed biodiversity loss at different trophic levels. Ecology Letters, 13, 597-605. https://doi. org/10.1111/j.1461-0248.2010.01457.x

Landi, P., Minoarivelo, H. O., Brännström, A., Hui, C., \& Dieckmann, U. (2018). Complexity and stability of ecological networks: A review of the theory. Population Ecology, 60, 319-345. https://doi.org/10.1007/ s10144-018-0628-3

Loreau, M., Naeem, S., Inchausti, P., Bengtsson, J., Grime, J. P., Hector, A. et al (2001). Biodiversity and Ecosystem Functioning: Current Knowledge and Future Challenges. Science, 294, 804-808. https:// doi.org/10.1126/science.1064088

Martin, M. (2011). Cutadapt removes adapter sequences from highthroughput sequencing reads. EMBnet.journal, 17, 10-12.

Martinson, H. M., \& Fagan, W. (2014). Trophic disruption: A meta-analysis of how habitat fragmentation affects resource consumption in terrestrial arthropod systems. Ecology Letters, 17, 1178-1189. https:// doi.org/10.1111/ele.12305

Mazerolle, M. J. (2017) Model selection and multimodel inference based on (Q)AIC(c). R package version 2.1-1 [WWW Document]. Retrieved from http://cran.r-project.org/package=AICcmodavg [accessed on 2017]
Murcia, C. (1995). Edge effects in fragmented forests: Implications for conservation. Trends in Ecology \& Evolution, 10, 58-62. https://doi. org/10.1016/S0169-5347(00)88977-6

Nentwig, W., \& Wissel, C. (1986). A Comparison of prey lengths among spiders. Oecologia, 68, 595-600. https://doi.org/10.1007/BF00378777

Nyffeler, M., \& Birkhofer, K. (2017). An estimated 400-800 million tons of prey are annually killed by the global spider community. The Science of Nature, 140, 30.

O'Rorke, R., Lavery, S., \& Jeffs, A. (2012). PCR enrichment techniques to identify the diet of predators. Molecular Ecology Resources, 12, 5-17.

O'Brien, M. J., Brezzi, M., Schuldt, A., Zhang, J.-Y., Ma, K., Schmid, B., \& Niklaus, P. A. (2017). Tree diversity drives diversity of arthropod herbivores, but successional stage mediates detritivores. Ecology and Evolution, 7, 8753-8760. https://doi.org/10.1002/ece3.3411

Perring, M.P., Hertzog, L. R., DeGroote,S.R.E.etal(2021). Overstoreycomposition shapes across-trophic level community relationships in deciduous forest regardless of fragmentation context. Journal of Ecology, 2021(109), 1591-1606. https://doi.org/10.1111/1365-2745.13580

Pompanon, F., Deagle, B. E., Symondson, W. O. C., Brown, D. S., Jarman, S. N., \& Taberlet, P. (2012). Who is eating what: Diet assessment using next generation sequencing. Molecular Ecology, 21, 1931-1950. https://doi.org/10.1111/j.1365-294X.2011.05403.x

Price, P. W. (2002). Resource-driven terrestrial interaction webs. Ecological Research, 17, 241-247. https://doi. org/10.1046/j.1440-1703.2002.00483.x

R Core Team (2018). R: A language and environment for statistical computing. R Foundation for Statistical Computing.

Rand, T. A., Tylianakis, J. M., \& Tscharntke, T. (2006). Spillover edge effects: The dispersal of agriculturally subsidized insect natural enemies into adjacent natural habitats. Ecology Letters, 9, 603-614. https://doi.org/10.1111/j.1461-0248.2006.00911.x

Ratnasingham, S., \& Hebert, P. (2007). BOLD: The barcode of life data system. Molecular Ecology Notes, 7, 355-364. www.barcodinglife.org

Ratnasingham, S., \& Hebert, P. (2013). A DNA-based registry for all animal species: The barcode index number (BIN), System. PLoS ONE, 8(7), e66213. https://doi.org/10.1371/journal.pone.0066213

Rognes, T., Flouri, T., Nichols, B., Quince, C., \& Mahé, F. (2016). VSEARCH : A versatile open source tool for metagenomics. PeerJ, 4, e2584.

Rzanny, M., Kuu, A., \& Voigt, W. (2013). Bottom - up and top - down forces structuring consumer communities in an experimental grassland. Oikos, 122, 967-976. https://doi. org/10.1111/j.1600-0706.2012.00114.x

Scherber, C., Eisenhauer, N., Weisser, W. W., Schmid, B., Voigt, W., Fischer, M., Schulze, E.-D., Roscher, C., Weigelt, A., Allan, E., Beßler, H., Bonkowski, M., Buchmann, N., Buscot, F., Clement, L. W., Ebeling, A., Engels, C., Halle, S., Kertscher, I., ... Tscharntke, T. (2010). Bottom-up effects of plant diversity on multitrophic interactions in a biodiversity experiment. Nature, 468, 553-556. https://doi. org/10.1038/nature09492

Scherber, C., Vockenhuber, E. A., Stark, A., Meyer, H., \& Tscharntke, T. (2014). Effects of tree and herb biodiversity on Diptera, a hyperdiverse insect order. Oecologia, 174, 1387-1400. https://doi. org/10.1007/s00442-013-2865-7

Schielzeth, H. (2010). Simple means to improve the interpretability of regression coefficients. Methods in Ecology and Evolution, 1, 103-113. https://doi.org/10.1111/j.2041-210X.2010.00012.x

Schmidt, M., Jochheim, H., Kersebaum, K.-C., Lischeid, G., \& Nendel, C. (2017). Gradients of microclimate, carbon and nitrogen in transition zones of fragmented landscapes - a review. Agricultural and Forest Meteorology, 232, 659-671. https://doi.org/10.1016/j.agrfo rmet.2016.10.022

Schmidt, N. M., Mosbacher, J. B., Eitzinger, B., Vesterinen, E. J., Roslin, T., \& Schmidt, N. M. (2018). High resistance towards herbivore-induced habitat change in a high Arctic arthropod community. Biology Letters, 14, 20180054. https://doi.org/10.1098/rsbl.2018.0054 
Schneider, J. M., \& Vollrath, F. (1998). The effect of prey type on the geometry of the capture web of Araneus diadematus. The Science of Nature, 85, 391-394. https://doi.org/10.1007/s001140050521

van Schrojenstein Lantman, I. M., Hertzog, L. R., Vandegehuchte, M. L., Martel, A., Verheyen, K., Lens, L., \& Bonte, D. (2020). Forest edges, tree diversity and tree identity change leaf miner diversity in a temperate forest. Insect Conserv Divers, 13, 10-22. https://doi. org/10.1111/icad.12358

Sensenig, A., Agnarsson, I., Gondek, T. M., \& Blackledge, T. A. (2010). Webs in vitro and in vivo: Spiders alter their orb-web spinning behavior in the laboratory. Journal of Arachnology, 38, 183-191. https://doi. org/10.1636/Hi09-34.1

Smedt, P. D., Baeten, L., Berg, M. P., Gallet-moron, E., Brunet, J., Cousins, S. A. O. et al (2018). Desiccation resistance determines distribution of woodlice along forest edge- to-interior gradients. European Journal of Forest Research, 85, 1-3.

Southwood, T. R. E., Wint, G. R. W., Kennedy, C. E. J., \& Greenwood, S. R. (2004). Seasonality, abundance, species richness and specificity of the phytophagous guild of insects on oak (Quercus) canopies. European Journal of Entomology, 101, 43-50. https://doi. org/10.14411/eje.2004.011

Staudacher, K., Rennstam Rubbmark, O., Birkhofer, K., Malsher, G., Sint, D., Jonsson, M., \& Traugott, M. (2018). Habitat heterogeneity induces rapid changes in the feeding behaviour of generalist arthropod predators. Functional Ecology, 23, 809-819. https://doi. org/10.1111/1365-2435.13028

Tew, E. R., Adamson, A., \& Hesselberg, T. (2015). The web repair behaviour of an orb spider. Animal Behaviour, 103, 137-146. https://doi. org/10.1016/j.anbehav.2015.02.016

Thébault, E., \& Loreau, M. (2005). Trophic Interactions and the Relationship between Species. The American Naturalist, 166, E95-E114.

Tiede, J., Wemheuer, B., Traugott, M., Daniel, R., Tscharntke, T., Ebeling, A. et al (2016). Trophic and Non-Trophic Interactions in a Biodiversity Experiment Assessed by Next- Generation Sequencing. PLoS One, 11, e0148781.

Untergasser, A., Cutcutache, I., Koressaar, T., Ye, J., Faircloth, B. C., Remm, M., \& Rozen, S. G. (2012). Primer3 - new capabilities and interfaces. Nucleic Acids Research, 40, 1-12. https://doi.org/10.1093/ nar/gks596

Vehviläinen, H., Koricheva, J., \& Ruohomäki, K. (2008). Effects of stand tree species composition and diversity on abundance of predatory arthropods. Oikos, 117, 935-943. https://doi. org/10.1111/j.0030-1299.2008.15972.x

Venner, S., \& Casas, J. (2005). Spider webs designed for rare but lifesaving catches. Proceedings of the Royal Society Biological Sciences, 272, 1587-1592. https://doi.org/10.1098/rspb.2005.3114
Vesterinen, E. J., Lilley, T., Laine, V. N., \& Wahlberg, N. (2013). Next Generation Sequencing of Fecal DNA Reveals the Dietary Diversity of the Widespread Insectivorous Predator Daubenton's Bat (Myotis daubentonii) in Southwestern Finland. PLoS One, 8, 1-14. https://doi. org/10.1371/journal.pone.0082168

Vesterinen, E. J., Lilley, T. M., Puisto, A. I. E., \& Blomberg, A. S. (2018). Table for five, please: Dietary partitioning in boreal bats. Ecology and Evolution, 8, 10914-10937. https://doi.org/10.1002/ece3.4559

Vesterinen, E. J., Ruokolainen, L., Wahlberg, N., Peña, C., Roslin, T., Laine, V. N. et al (2016). What you need is what you eat? Prey selection by the bat Myotis daubentonii. Molecular Ecology, 25, 1581-1594.

Vestheim, H., \& Jarman, S. N. (2008). Blocking primers to enhance PCR amplification of rare sequences in mixed samples - a case study on prey DNA in Antarctic krill stomachs. Frontiers in Zoology, 11, 1-11. https://doi.org/10.1186/1742-9994-5-12

Vollrath, F. (1999). Biology of spider silk. International Journal of Biological Macromolecules, 24, 81-88. https://doi.org/10.1016/S0141 -8130(98)00076-2

Woodward, G., \& Hildrew, A. G. (2002). Body-size determinants of niche overlap and intraguild predation within a complex food web. Journal of Animal Ecology, 71, 1063-1074. https://doi. org/10.1046/j.1365-2656.2002.00669.x

Ye, J., Coulouris, G., Zaretskaya, I., Cutcutache, I., Rozen, S., \& Madden, T. L. (2012). Primer-BLAST: A tool to design target-specific primers for polymerase chain reaction. BMC Bioinformatics, 13, 134. https://doi. org/10.1186/1471-2105-13-134

Zeale, M. R. K., Butlin, R. K., Barker, G. L. A., Lees, D. C., \& Jones, G. (2011). Taxon-specific PCR for DNA barcoding arthropod prey in bat faeces. Molecular Ecology Resources, 11, 236-244. https://doi. org/10.1111/j.1755-0998.2010.02920.x

\section{SUPPORTING INFORMATION}

Additional supporting information may be found online in the Supporting Information section.

How to cite this article: van Schrojenstein Lantman IM, Vesterinen EJ, Hertzog LR, et al. Body size and tree species composition determine variation in prey consumption in a forest-inhabiting generalist predator. Ecol Evol. 2021;11:8295-8309. https://doi.org/10.1002/ece3.7659 